\title{
The origin and drivers of Neotropical plant and tetrapod diversification
}

\author{
Andrea Meseguer ${ }^{1}$, Alice Michel ${ }^{2}$, Pierre-Henri Fabre ${ }^{3}$, Oscar Perez Escobar ${ }^{4}$, Guillaume \\ Chomicki $^{5}$, Ricarda Riina ${ }^{6}$, Alexandre Antonelli ${ }^{4}$, Carlos Jaramillo ${ }^{7}$, Pierre Olivier \\ Antoine $^{8}$, Frederic Delsuc ${ }^{2}$, and Fabien Condamine ${ }^{9}$ \\ ${ }^{1}$ INRA \\ ${ }^{2}$ Centre National de la Recherche Scientifique \\ ${ }^{3}$ Universite de Montpellier \\ ${ }^{4}$ Royal Botanic Gardens Kew \\ ${ }^{5}$ University of Oxford \\ ${ }^{6}$ Real Jardín Botánico de Madrid CSIC \\ ${ }^{7}$ STRI \\ ${ }^{8}$ University of Montpellier \\ ${ }^{9} \mathrm{CNRS}$
}

May 5, 2020

\begin{abstract}
The assembly of the world's most biodiverse region, the Neotropics, was traditionally considered the result of long-term environmental stability. Studies gathered during the last decades suggest that environmental "instability" instead, specially the dramatic modifications caused by the uplift of the Andes, was responsible of the Neotropical diversity. Yet a comprehensive understanding has been hindered by a lack of large-scale comparative data across wide phylogenetic and ecological contexts. Here, we evaluate the timing and drivers of Neotropical diversification in a large sample of Neotropical clades: 150 phylogenies (12,524 species) of seed plants and major tetrapods (amphibians, mammals, squamates, and birds). We unveil five trends: (1) biodiversity levels before the Quaternary were comparable (or higher) to those of the present,; (2) half of the clades diversified at constant rates; (3) past environmental variations correlate with diversification changes in $37 \%$ of the lineages, but with contrasting responses: (4) birds and mammals diversified extensively during warm periods and global cooling resulted in synchronized slowdowns of diversification; plant diversification generally increased during cooling; and (5) the rise of the Andes mostly impacted amphibians and squamates. Our study suggests that environmental instability over macroevolutionary scales may in fact act as a driving force of Neotropical diversification.
\end{abstract}

\section{Introduction}

Comprising South America, Central America, tropical Mexico and the Caribbean Islands, the Neotropics are arguably the most biodiverse region on Earth. This region not only includes the largest tropical rainforest, Amazonia, but also eight of the 34 known biodiversity hotspots (Mittermeier et al. 2011). The tropical Andes, in particular, is considered the most species-rich biome in the world for amphibians, birds, and plants, Mesoamerica and the Caribbean Islands are the richest regions for squamates, while Amazonia is seen as the primary biogeographic source of Neotropical biodiversity (Antonelli et al. 2018c). The age and underlying causes of the extraordinary Neotropical biodiversity represent one of the most debated topics in evolutionary ecology (Haffer 1969; Simpson 1980; Gentry 1982), but the mechanisms behind its origin 
and maintenance remain elusive (Leigh Jret al. 2004; Hoorn et al. 2010; Antonelli \& Sanmartín 2011; Rull 2011a).

A long-held tenet was that the outstanding levels of Neotropical diversity were mainly generated during the Quaternary (i.e. the past 2.6 million years [Myrs]), as the product of recent environmental fluctuations (Haffer 1969; Rull 2011a). However, this hypothesis was challenged by the age of the most recent common ancestors (MRCA) of Neotropical taxa (Hoorn et al. 2010) and fossil studies showing a fossil record significantly more diverse in the Eocene than posteriorly (Jaramillo et al. 2006). Although recent studies show that modern climate (Moritz et al. 2000; Rull 2011a; Rowanet al. 2019) and intrinsic biological traits (Smith et al.2014) could have contributed to explain the maintenance of Neotropical diversity during the last few million years, megadiversity levels in the Neotropics probably existed before the Quaternary. Under this understanding, short temporal scales might be limited to study this pattern and historical eco-evolutionary factors need be investigated to understand the origin and evolution of the Neotropical diversity.

For a long time, the long-term stability and large extension of the tropical biome across the South American continent and tens of million years of continental isolation have been argued as the main factors promoting the gradual accumulation of lineages in the Neotropics (Wallace 1878; Stebbins 1974; Simpson 1980). Yet, new studies gathered during the last decade suggest instead that long-term environmental instability - geological and environmental perturbations together with intermittent land connections, mostly during the Neogene have been responsible for the outstanding Neotropical diversity (Mittelbachet al. 2007; Hoorn et al. 2010; Rull 2011a; Antonelliet al. 2018b).

Among all potential environmental perturbations, the orogenesis of the Andes and associated geomorphological and ecological modifications has become paradigmatic for explaining Neotropical biodiversity (Gentry 1982; Hughes \& Eastwood 2006; Hoorn et al. 2010; Luebert \& Weigend 2014; Antonelli et al. 2018a; Esquerré et al.2019). Andean uplift began in the Central Andes 65 Myrs ago (Mya) as a result of subduction of the Nazca plate along the Pacific margin, and in the Northern Andes 23 Mya, with the collision of the Pacific plate. Uplift then intensified 12-4.5 Mya (Garzione et al. 2008; Hoorn et al. 2010; Chen et al. 2019). The Andean orogeny deeply affected regional climate, hydrological conditions and landscape evolution at a continental level, with increased eastern rainfall and sediment flux into Amazonia (Hoorn et al. 1995; Armijo et al. 2015). This process resulted in the modern configuration of the Amazon drainage basin and fluvial system less than 10 Mya, and contributed to the formation of the "dry diagonal" Caatinga-Cerrado belt (Blisniuket al. 2005; Hoorn et al. 2010, 2017). This tectonic rearrangement also led to the closure of the Central American Seaway 10 Mya (Jaramillo 2018).

The dynamic landscape caused by the Andean uplift has been postulated to have a major effect on Neotropical diversification by (i)increasing habitat and environmental heterogeneity (today all major biomes appear in the region, e.g. tropical forests, deserts, and high elevation grasslands), (ii) favoring isolation and thus allopatric speciation in montane populations separated by deep valleys, lowland populations on either side of the emerging mountains, and Amazonian populations separated by new riverine barriers (Flantuaet al. 2019), and by (iii) creating the longest latitudinally-elongated corridor for biotic montane dispersal (Antonelliet al. 2009; Luebert \& Weigend 2014). As such, Andean uplift has been associated with the explosive radiation of plants, insects, and tetrapods (Weir 2006; Drummond et al. 2012; Lagomarsino et al. 2016; Pérez-Escobar et al. 2017; Pouchon et al. 2018; Chazot et al. 2019; Esquerré et al. 2019), and with increased rates of biotic interchange (Santos et al. 2009; Fjeldså et al. 2012; Antonelli et al. 2018c; Baconet al. 2018).

Analyses of the fossil record also suggest that Neotropical diversity has been strongly linked to temperature (Hoorn et al. 1995; Jaramillo et al. 2006). Global temperatures were warmer during the Cretaceous and early Paleogene, a period punctuated with hyperthermal events, such as the Paleocene-Eocene Thermal Maximum (PETM) 56 Mya. The late Paleogene marks the onset of a long-term cooling trend that was accelerated at the beginning of the Quaternary leading to the glaciation-interglaciation climate of the past 2.6 Myrs (Zachos et al. 2008; Veizer \& Prokoph 2015). In South America, global cooling promoted the expansion of open habitats and the subsequent establishment of fire regimes in the Cerrado savannas (Simonet al. 2009; Antoine et al. 2013). These past climatic events are also thought to have shaped Neotropical diversification 
(Pinto-Ledezma et al. 2017). Plant diversity inferred from fossil morphotypes increased with warming periods during the Eocene, and decreased sharply with subsequent cooling (Hoorn et al. 1995; Jaramillo et al. 2006). Quaternary glacial cycles have been considered to promote fragmentation in rainforest ecosystems and highaltitude habitats (e.g. through altitudinal shifts in Andean vegetation zones), which in turn contributed to geographical isolation and diversification (Haffer 1969; Rull 2011a; Flantua et al.2019). Diversification of Neotropical clades have also been attributed to more ancient climatic events, such as the PETM and the cooling event subsequent to the Middle-Miocene climatic optimum (MMCO) (Hughes \& Eastwood 2006; Lagomarsino et al. 2016).

These alternative but non-exclusive models of diversification in the Neotropics have been difficult to tease apart empirically for two reasons. Firstly, there has been a lack of large-scale comparative data across wide phylogenetic and ecological contexts. Secondly, it has been challenging to develop environmentally explicit diversification models linking changes in the physical environment and species diversification (Condamine $e t$ al. 2013, 2019). Some studies have focused on particular Neotropical clades to infer their triggers of diversification (Lagomarsino et al. 2016; Esquerre et al. 2019), but given the vast heterogeneity of the region, general insights can only be provided if patterns of diversification are shared among Neotropical lineages. Here, we use a comparative phylogenetic data set containing 150 well-sampled species-level molecular phylogenies and 12,524 species. Our data set represents $\sim 60 \%$ of all estimated tetrapods and $\sim 7 \%$ of the known plant Neotropical diversity, which we use to evaluate the timing and drivers of Neotropical diversification at a continental scale. Our results reveal an ancient pre-Quaternary origin of Neotropical diversity, as well as striking effects of climatic and landscape changes on Neotropical diversification, with varying degrees of importance and effect depending on organismal biology and identity.

\section{Results}

Neotropical Phylogenetic Dataset. We constructed a dataset of 150 time-calibrated clades of Neotropical tetrapods and plants derived from densely sampled molecular phylogenies (Fig. 1 and SI Appendix 1 and Fig. S1). The dataset comprises 12,524 species divided into 6,255 species of plants, including gymnosperms and angiosperms (66 clades, representing $7 \%$ of the described Neotropical seed plants; SI Appendix, Table S1); 900 mammal species (12 clades, $75 \%$ of the Neotropical mammals; SI Appendix, Table S2); 2,216 bird species (32 clades, $59 \%$ of the Neotropical birds; SI Appendix , Table S3); 1,148 squamate species (24 clades, $33 \%$ of the Neotropical squamates; SI Appendix, Table S4); and 2,005 amphibian species (16 clades, $69 \%$ of the Neotropical amphibian diversity; SI Appendix, Table S5). Our dataset triplicates the data presented in previous meta-analyses of the Neotropics in terms of number of species (214 clades and 4450 species in ref. (Antonelliet al. 2018c), and quadruplicates it in terms of sampling (20.8 species per tree in ref. (Antonelli et al. 2018c) vs . 83.5 in our study). Each clade in our dataset included 7 to 789 species (mean $=83.5$ species), with $53 \%$ of the phylogenies including more than $50 \%$ of the described taxonomic diversity (sampling mean $=57 \%$; Fig. 1 and SI Appendix, Fig. S1). Clade ages of current Neotropical diversity range from 0.9 to 88.5 Myrs (mean $=30.4 \mathrm{Myrs}$ ), with the origin of current squamates (mean $=47.5 \mathrm{Myrs}$ ) and amphibians (mean $=66 \mathrm{Myrs}$ ) being comparatively older than the age of other groups $\left(\right.$ mean $_{\text {birds }}=18.1 \mathrm{Myrs}$, mean $_{\text {mammals }}$ $=25.6$, mean $_{\text {plants }}=22.5$ Myrs; Fig. 1 and SI Appendix, Fig. S1).

Diversification Dynamics in the Neotropics. To understand the drivers of Neotropical diversification we compared the fit of birth-death models applied to 150 phylogenies, including models where diversification rates are constant, vary through time, vary as a function of past global temperatures, or vary according to past Andean elevation (see Methods). Models assuming constant speciation and extinction rates through time best fit half of the phylogenies in our study (75 clades; 2,903 species; Fig. 2 and SI Appendix 2 and Table S6 and Fig. S2), often when clades are species-poor (Kruskal-Wallis chi-squared test: $\chi^{2}=53.675$, $\mathrm{df}=3, P=0.0 ;$ SI Appendix , Table S7 and Fig. S2). Phylogenies best fitting a constant model are also significantly younger than those fitting Andean uplift and temperature models $\left(\chi^{2}=41.96, \mathrm{df}=3, P=\right.$ 0.0 ), even though young clades do not tend to be species-poor (SI Appendix, Fig. S3). Taxon sampling does not differ significantly between the four model categories investigated here, suggesting that there is not a particular bias due to incomplete sampling in our results $\left(\chi^{2}=4.01\right.$, df $=3, P=0.26$; SI Appendix , 
Table S7 and Fig. S2).

In the other half of the phylogenies analyzed here, representing most of the Neotropical diversity (75 trees; 9,621 species; Fig. 3 andSI Appendix, Table S8), we find variation in diversification rates through time, with 42 clades $(4,486$ species) showing slowdowns of diversification and 33 increasing diversification $(5,135$ species). Rate variation is inferred from models that are able to capture the dependency of speciation and/or extinction rates over time (time-dependent models) or over an environmental variable (either temperature- or uplift-dependent models). Temperature-dependent models explain diversification in $26 \%$ of the phylogenies and $44 \%$ of the species sampled (5,487 species). Time-dependent models best fit $13 \%$ of the clades $(1,717$ species, $13 \%)$. Meanwhile uplift-dependent models explain $11 \%$ of the phylogenies $(2,417$ species, $19 \%)$ (Fig. 2and SI Appendix, Table S9), especially for ancient clades $\left(\chi^{2}=53.675, \mathrm{df}=3, P=0.0 ;\right.$ SI Appendix , Table S7 and Fig. S2). Seven of these clades have an Amazonean-centered distribution and are better fit by an uplift model.

We did not detect significant differences in diversification trends (i.e., increasing, constant, decreasing) estimated between tetrapod lineages living in distinct geographic ranges (Andean-centered, Amazoniancentered, or other), elevations (lowland $[<1000 \mathrm{~m}]$, montane $[1000-3000 \mathrm{~m}]$, or highland $[>3000 \mathrm{~m}]$ ) or vegetation types (open tropical vegetation, tropical forest, or non-tropical vegetation). For plants, we perceived, however, a marginally non-significant difference in the frequency of Amazonian-centered clades showing decreasing diversification through time in comparison with Andean-centered and lineages with other distribution $\left(\chi^{2}=5.69, \mathrm{df}=2, P=0.058\right)$.

\section{Discussion}

The Origin of Neotropical Biodiversity. All evidence generated in our analyses suggests that Neotropical biodiversity attained outstandingly high levels prior to the Quaternary. The age of the MRCA of most clades analyzed here (146 clades out of 150, 97\%) largely predates the Quaternary (Fig. 1 ; mean age of 30.4 Myrs), supporting the results of (Hoorn et al. 2010). The MRCA of clades and genera, however, do not inform on the diversification of their descendant species (Rull 2011b). This is instead informed by the diversification rates calculated here, which for most Neotropical lineages have remained constant through time (75 clades, 50\%; 2903 species, $23 \%$ ) or were higher in the past and diversification decreased toward the present (42 clades, 28\%; 4486 species, 36\%) (Fig. 3 ). This result suggests that the total number of species in the Neotropics was probably as high (or higher) before the Quaternary than today, a result previously only reported from the fossil record (Jaramillo et al. 2006; Salas-Gismondi et al. 2015).

Diversification Drivers for Tetrapods. A substantial number of Neotropical tetrapod clades studied here (44\%) evolved under a constant rate during the Cenozoic (Fig. 2 ), although this proportion is smaller when the number of species is accounted for (1,204 species, 19\%). Phylogenies best fitting constant models in our study tend to be smaller and younger than phylogenies fitting other models, and as so, we find a higher proportion of bird and mammal clades' diversification dynamics $(>50 \%)$ explained by constant-rate models than amphibian and squamates clades (<30\%,Fig. 1 and SI Appendix, Table S7 and Fig. S2). This could be partly explained by the observed differences in clade ages between these groups, with younger clades having, arguably, less time to being exposed to geological and environmental changes during their history (Smith et al. 2014), but also by our reduced power to detect rate variation as the number of species decreases (Davis et al. 2013). The remaining tetrapod diversification is generally best explained by speciation rates decreasing through time and extinction remaining constant (Fig. 3 and SI Appendix, Table S9), a pattern that is especially manifest in endotherms, and among them in birds. Regardless of their ecology or distribution, all bird clades exhibit diversification slowdowns (Fig. 3 and SI Appendix, Tables S3 and S9).

The pattern of decreasing diversification in Neotropical endotherms is consistent with previous studies suggesting a general trend for slowdowns in speciation at continental scales and across taxonomic groups (McPeek 2008; Phillimore \& Price 2008; Morlon et al.2010; Luzuriaga-Aveiga \& Weir 2019), which has been often interpreted as the signal of ecological limits on the number of species within a clade (Rabosky 2009). Among the phylogenies supporting diversification slowdowns here, time-dependent models explain $8 \%$ of all tetrapod 
phylogenies, but the proportion is highest for mammals (25\%,Fig. 2 and SI Appendix, Table S10 and Figs S4-5). Time-dependent models with decreasing speciation have been suggested to be a good approximation of diversity-dependent diversification (Raboskyet al. 2014). Our results lend support to an alternative explanation for diversification slowdowns: the idea that clades fail to keep pace with a changing environment (Moen \& Morlon 2014; Condamineet al. 2019). Our temperature-dependent models explain a substantial proportion of phylogenies supporting diversification slowdowns in our study (17\% of mammal and $38 \%$ of birds; Fig. 4 and SI Appendix, Figs S6-7). The positive correlation between diversification and past temperature indicates that these groups diversified more during periods of global warming such as the greenhouse Eocene or the MMCO, and speciation decreased during colder periods (such as the Eocene-Oligocene transition and the late Miocene onwards).

Temperatures can influence diversification in different ways. According to the Metabolic Theory of Biodiversity, high temperatures can increase enzymatic activity, generation times and mutation rates (Gilloolyet al. 2001), which may in turn affect diversification positively, and conversely (Allen et al. 2006; Condamine et al. 2019). Climate cooling could also decrease global productivity, resource availability, and population sizes (Mayhew et al. 2012) or even species interactions (Jaramillo \& Cárdenas 2013; Chomickiet al. 2019). Reduction of the tropical forest biome (Jaramillo 2019) could have also contributed to this pattern of decreasing diversification in association with climate changes, caused by decreased precipitation in the Neotropics during Cenozoic cooling (Silva et al. 2019). Only one group of endotherms, the New World monkeys (Platyrrhini), had increased diversification as temperature dropped. This result could reflect the role of Quaternary events on primate speciation (Rull 2011a), or could, however, be an artifact of taxonomy over splitting species in this clade (Springer et al. 2012).

Compared with endotherms, ectotherm tetrapods show a mixed diversification trend (Fig. 3 and SI Appendix, Table S8). We find a similar fraction of amphibians decreasing and increasing diversification rates through time (668 species and 5 phylogeniesvs. 823 species and 6 phylogenies, respectively). In squamates, the diversification of most clades has decreased, but for a non-negligible proportion it increased (679 species and 13 phylogeniesvs. 353 species and 4 phylogenies). Contrasting with endotherms and plants (see below), the triggers of rate variations in ectotherm diversification are mostly associated with the Andean orogeny ( $50 \%$ of amphibian clades and 1,166 species; $33 \%$ of squamate clades and 663 species) rather than with global temperature changes or time (Figs. 2, 5 and SI Appendix, Figs. S6 and S7 and Tables S6 and S9). This is in agreement with the dominant view on Neotropical ectotherm diversification (Santos et al. 2009; Hutter et al. 2013, 2017; Esquerré et al. 2019).

The Andes host twice the amphibian richness as the entire Amazonian lowland rain forest, with more endemic frog species than any other region in the world (Hutter et al. 2017). They also comprise the third most endemic squamate fauna, after the Caribbean Islands and Madagascar (Mittermeier et al. 2011). Interestingly, we find that diversification in many lineages (i.e., 649 amphibian and 353 squamate species) correlated positively with the Andean uplift, such that cladogenesis progressively increased with the orogeny (Figs. 2, 5 ). Some of these clades show an Andean-centered distribution, such as Liolaemidae and Tropiduridae lizards or Centrolenidae frogs, but others are predominately distributed outside the Andes such as Leptodactylidae frogs or Hoplocercidae lizards (SI Appendix , Tables S4-5). Sustained diversification in the context of Andean orogeny into and out of the Andean region could be explained by increasing thermal and environmental gradients from equatorial areas to Patagonia or in a west-east gradient, as it has been suggested to affect Leptodactylidae and other frogs (Fouquet et al. 2014; Moen \& Wiens 2017). Other possible correlates include changes in elevational distributions of lineages and concomitant shifts in climatic regimes (Kozak \& Wiens 2010; Hutter et al. 2017), recurrent migrations from (and within) the Andes into other regions, and allopatric fragmentation (Santos et al. 2009; Esquerré et al. 2019). The explosive generation of new land area that occurs with mountain building could also explain this pattern (Elsen \& Tingley 2015; Antonelli et al. 2018b), e.g. , each small ravine down the mountain has a microtopography with a variety of slopes in multiple directions.

In a significant proportion of ectotherm clades, however, we also detected that diversification was elevated only during the early stages of the orogeny and then decreased with progressive uplift (i.e.,negative correlation 
between diversification and Andean orogeny for 472 amphibian and 310 squamate species; Fig. 5 and SI Appendix, Figs. S6 and S7), in agreement with diversification slowdowns detected in recent studies (Santos et al. 2009). These include lineages that are diverse in the Andes, such as dendrobatid frogs, but also nonAndean lineages, such as Odontophrynidae frogs or Leiosauridae and Xantusiidae lizards, which abound in the Cerrado, Chaco, temperate South America, and Mesoamerica.

Andean uplift started in the late Eocene with the formation of moderate elevation uplands $(1,000-1,500 \mathrm{~m})$ in a non-continuous belt, and then accelerated in the late Miocene, with the majority of the Tropical Andes reaching its modern elevation 4.5 Mya (Garzioneet al. 2008; Hoorn et al. 2010; Chen et al. 2019). Initial Andean uplift might have stimulated diversification in the lowland transition zone, with new ecological opportunities in tropical-like habitats formed at moderate elevation and increased rates of geographical isolation for species with cross-Andean distributions (Santos et al. 2009). Post-Miocene uplifts, however, built a major ecological and geological barrier for biotic dispersals of many groups, with strong physiological constraints limiting adaptations to new upland environments, or dispersal across unsuitable habitats (Santoset al. 2009; Olalla-Tarraga et al. 2011; Hutter et al. 2013; Pie et al. 2017). Taken together, these results suggest that elevation of the Andes impacted ectotherm diversification at the continental scale.

Diversification Drivers for Plants. In contrast to tetrapods, the diversification of a significant fraction of Neotropical plants shows an expanding trend toward the present (4,019 species, $64 \% ; 22$ clades, 33\%), either due to increasing speciation, decreasing extinction, or both (Fig. 3 and SI Appendix, Table S9). Another substantial proportion of plants evolved under a constant rate model (1,699 species, 27\%; 38 phylogenies, $58 \%$ ). Only a small proportion of Neotropical plant diversity experienced slowdowns of diversification (537 species, $8.6 \%$; 6 phylogenies, $9 \%$ ). Changes in plant diversification are also mostly associated with paleotemperatures (16 clades; $24 \%$ ) and with time alone (11 clades; 16\%), while the effect of the Andes is negligible (1 clade, Gesnerioideae) (Figs. 2, 4 and SI Appendix, Figs S6 and S7). This result is surprising given that Andean uplift has often been considered the main driver behind the radiation of Neotropical plants, especially in the Paramo, but also in other regions (Hughes \& Eastwood 2006; Antonelli et al. 2009; Drummond et al. 2012; Luebert \& Weigend 2014; Lagomarsino et al. 2016; Perez-Escobar et al. 2017; Bacon et al. 2018; Pouchon et al. 2018). Lineages including species distributed in the Paramo are not well represented in this study, but the few included here - Lupinus(Fabaceae), centropogonids (Campanulaceae), Pleurothalis andStelis (Orchidaceae), Solanum, Cestrum, and Sessea(Solanaceae) - do not follow an uplift model. This result contrasts with a previous study for Cymbidieae orchids supporting uplift-dependent diversification (Perez-Escobar et al. 2017), while diversification in this clade is best explained by temperature-dependent models in our study (SI Appendix, Table S9). Results are however not directly comparable as ref. (PerezEscobar et al. 2017) only evaluated uplift models. Similarly, centropogonids diversification is best explained by temperature-dependent models in ref. (Lagomarsinoet al. 2016), but by time-dependent models in our study (SI Appendix, Table S9). Time-dependent models are not evaluated in previous studies (Lagomarsino et al. 2016; Perez-Escobar et al. 2017), though these models probably represent more realistic null hypotheses than constant-rate scenarios, especially when half of the diversity in our study is found to have changed diversification rates through time (Fig. 2 ).

Among the plant clades increasing diversification rates through time, in 10 phylogenies $(15 \%$ of the clades; 2,180 species, $35 \%$ ), we found a negative correlation between diversification and temperature changes, indicating that these groups diversified more during cold periods and due to increasing speciation or decreasing extinction (Figs. 3, 4 and SI Appendix, Figs. S4-6). In the other 11 clades (1251 species, 20\%), diversification increased as a function of time alone (SI Appendix, Table S10), and generally due to decreases of extinction while speciation remained constant (SIAppendix, Table S9).

Plant phylogenies increasing diversification rates through time mostly correspond to clades distributed in the Andes, Choco and Central America - also termed "Andean- centered" groups (Gentry 1982) - from lowlands to highlands, such as Bactris palms (Arecaceae),Fuchsia (Onagraceae), or Cymbidieae orchids, among others (SI Appendix, Table S9). Many species within Andean-centered groups were likely able to adapt to the new conditions that increasingly appeared in the mountain foothills as the Andes uplifted 
and global temperatures dropped (Luebert \& Weigend 2014; Antonelli et al.2018b). It has been proposed that the first Quaternary glaciation could have acted as a major evolutionary bottleneck, whereby many warm-adapted lineages succumbed, while those that survived could have diversified and better cope with subsequent climatic oscillations (Silva et al.2018). Cenozoic climate cooling could also have created a "biotic corridor" for pre-adapted lineages to montane conditions to increase their range and colonize new montane environments (Antonelli et al. 2009; Perez-Escobar et al. 2017; Meseguer et al.2018). Many iconic highelevation Andean clades (e.g. Espeletia) had major radiations within the past 2.5 Myrs (Madrinan et al.2013; Pouchon et al. 2018), about 2 Myrs after the Andes had reached their modern elevation, suggesting that the onset of the Quaternary climate could have played a much stronger role in increasing speciation rates than the generation of high topography in itself. In addition, some of these clades represent textbook examples of ongoing explosive radiations; e.g. centropogonids (Lagomarsino et al. 2016), Lupinus (Hughes \& Eastwood 2006; Drummond et al. 2012), and Inga (Richardson et al. 2001). Their diversification has been previously associated with biotic drivers, such as species interactions (Kursar et al. 2009), the evolution of key adaptations (Drummond et al. 2012), or pollination syndromes (Lagomarsino et al. 2016). Although we have not explicitly tested the impact of intrinsic biological traits in the generation of this diversity, these results add support to the role of climate and biotic factors as not mutually exclusive drivers of macroevolutionary changes in the Neotropics, with the rise of the Andes acting mostly indirectly by providing the necessary conditions for species to expand and diversify in new climatic regimes.

In contrast, we detected six clades (537 species) that have decreased diversification, all associated with global cooling (includingSideroxylon [Sapotaceae], Guatteria[Annonaceae], Myrcia [Myrtaceae], among others). These clades are mostly distributed in lowland regions of Amazonia, the Brazilian and Guiana Shields the Amazonian-centered elements in Gentry's sense (Gentry 1982) (SI Appendix, Table S9). These groups diversified more during warm periods and climate cooling negatively impacted their diversification, a result consistent with paleobotanical studies showing a positive correlation between Neotropical plant paleodiversity and past temperatures (Jaramilloet al. 2006). Slowdowns of diversification were mainly due to decreases in speciation (Fig. 4 and SI Appendix, Figs. S5 and S6). Such pattern could be explained by decreases in primary productivity, but also by the expansion of several biomes, including Paramo, cloud forests, savannas, and dry/xerophytic forest at the expense of the reduction of the rainforest during the late Neogene (Jaramillo 2019).

Conclusion. Environmental perturbations have long been recognized as fundamental for regulating diversity, although progress toward understanding how has been slow. Here, we demonstrate that diversification for a significant fraction of Neotropical clades correlates with deep-time environmental trends, especially with temperature changes and to a lesser extent with Andean uplift. The effect of these environmental perturbations extends to the continental scale, modulating the pace of Neotropical diversification across organisms and biomes. Yet, the specific mechanisms by which they impact diversification are clade-dependent and remain to be understood. The other fraction of Neotropical diversity evolved at constant rates or is associated with different extrinsic/intrinsic factors.

Our results have implications for discussing the future of biodiversity in the context of current environmental changes, and on how it might recover from human-induced extinction. As global change accelerates, ecosystems will face an increasing rate of perturbations, e.g.temperatures increase, drought or habitat loss, with current deforestation rates staggering across all Neotropical biomes. If one quarter of the Neotropical diversity in our study ( $\sim 3000$ species) follows a constant diversification mode as in the past, it may take tens of millions of years for biodiversity to reach its pre-extinction level. For most of the remaining Neotropical diversity, but especially tetrapods and Amazonian plants, past climate cooling triggered coordinated slowdowns of their speciation rates, suggesting that the pace of diversification in the world insignia of biodiversity, the Neotropics, has been in deceleration. Whilst this study found that ancient climate warming triggered increases in diversification on these lineages, this relationship must not be extended to the present, as the pace of current environmental changes is the fastest in geological history and acting in synergy with multiple biotic stressors lacking past equivalents (Condamine et al. 2013). 


\section{Materials and Methods}

Additional data and methodology are described in SI Appendix .

Data Compilation. We extracted Neotropical clades that included at least $80 \%$ of the species distributed in the Neotropics as defined in (Antonelli et al. 2018c). From large-scale phylogenies, we relied on the time-calibrated phylogenies of frogs and toads (Hutter et al. 2017), salamanders (Pyron et al. , 2013; Pyron, 2014), Squamata (lizards and snakes) (Pyron \& Burbrink 2014), birds (Jetz et al. 2012) (including only species for which genetic data was available), mammals (Bininda-Emonds et al. , 2007; Kuhn et al. , 2011), and plants (Zanne et al. 2014). In addition, phylogenies of particular lineages not represented in the global trees (or with improved taxon sampling) were obtained from published studies (SI Appendix, Tables S1-5) or reconstructed de novo (for caviomorph rodents, including 199 species, and phyllostomid bats, 170 species; see SI Appendix ). However, whenever possible, we preferred to extract phylogenies from a single dated tree rather than performing a meta-analysis of individual trees coming from different sources (e.g., ref. (Hoorn et al.2010; Jansson et al. 2013)), such that divergence times would be comparable. In addition, this procedure allows reducing the bias of focusing on particular taxonomic levels (i.e., individual studies often focus on genera) and thus comparing lineages of similar ages (Wiens 2017). When the most inclusive Neotropical clade was over the family rank, or for extremely species-rich groups, like the family Solanaceae with more than 2,700 species, we split the phylogenies into smaller clades (e.g., tribes) to take into account the heterogeneity of evolutionary histories likely characterized by different morphologies and key adaptations.

Diversification Analyses. We designed and applied a series of 10 birth-death diversification models estimating speciation $(\lambda)$ and extinction $(\mu)$ rates for each of the 150 phylogenies with the R-package RPANDA 1.3 (Morlon et al. 2016). We first fitted a constant-rate birth-death model (null model) and a set of three models in which speciation and/or extinction vary according to time (Morlon et al. 2011): $\lambda(\tau)$ and $\mu(\tau)$

- For time-dependent models, we measured rate variation for speciation and extinction with $a$ and $\beta$, respectively: $a$ and $\beta>0$ reflect decreasing speciation and extinction toward the present, respectively, while $a$ and $\beta<0$ indicate the opposite, increasing speciation and extinction toward the present.

We further investigated the effect of environmental changes, here approximated by mean global temperatures and paleo-elevations of the Andes (the main factors hypothesized behind the origin of Neotropical diversity). Temperature variations during the Cenozoic were obtained from global compilations of deep-sea oxygen isotope $\left(\delta^{18} \mathrm{O}\right)$ from ref. (Prokoph et al. 2008; Zachoset al. 2008), but also on other different paleotemperature curves, to assess the impact of paleotemperature uncertainty on our results (SI Appendix ). For Andean paleo-elevations we retrieved a generalized model of the paleoelevation history of the tropical Andes, compiled from several references (ref. (Lagomarsino et al. 2016) and references therein)). We examined whether speciation and/or extinction correlate with one of these variables using paleoenvironment-dependent diversification models (Condamine et al. 2013), which extends time-dependent models to account for potential dependencies between diversification rates and measured environmental variables. The elevation of the Andes caused dramatic modifications in Neotropical landscapes and could have impacted indirectly the diversification of non-Andean groups. Therefore, we decided to apply uplift models to all clades in our study, independently on whether their distribution is centered in the Andes or not. We fitted three models in which speciation and/or extinction vary continuously with temperature changes $(\lambda(T)$ and $\mu(T »$, and three others with the elevation of the Andes $\left(\lambda(A)\right.$ and $\mu\left(A \gg\right.$. In this case, $\lambda_{0}\left(\mu_{0}\right)$ is the expected speciation (extinction) rate under a temperature of $0^{\circ} \mathrm{C}$ (or a paleoelevation of $0 \mathrm{~m}$ for the uplift models). For the groups in which diversification was temperature- or uplift-dependent, we analyzed whether the speciation $(a)$ and extinction $(\beta)$ dependency was positive or negative. For temperature models, $a(\beta)>0$ reflect increasing speciation (extinction) with increasing temperatures, and conversely. For the uplift models, $\alpha(\beta)>0$ reflect increasing speciation (extinction) with increasing Andean elevations, and conversely. We accounted for missing species for each clade in the form of sampling fraction $(\rho)$ (Morlon et al. 2011) and assessed the strength of support of the models by computing Akaike information criterion (AICc), [?]AICc, and Akaike weights (AIC $\omega$ ) to select the best-fit model.

Finally, we tested the effect of clade age, size and sampling fraction on the preferred model using Kruskal- 
Wallis rank sum test and performed multiple pairwise-comparison between groups with corrections for multiple testing using Wilcoxon rank sum test. We also evaluate if the estimated diversification trends (i.e. , increasing, constant, decreasing) differ between lineages characterized by different geographic distributions, altitudinal ranges and habitat preferences (see SI Appendix ).

Our study focuses on the effects of environmental factors over diversity, and in this sense we did not directly assess the effect of biotic factors. Only few models of that type exist, and none explicitly incorporate species interactions within clades. The most relevant of such models are diversity-dependent models where the number of extant species in a clade affects diversification rates (Etienne et al.2012). We did not fit these models for three additional reasons: $(i)$ it is not straightforward to compare diversity-dependent models with other diversification models on the basis of AICc (Etienneet al. 2016); (ii) the sampling scheme currently implemented in diversity-dependent models assumes that exactly $n$ species are sampled ( $n$-sampling), while other models assume that each species is sampled with a fixed probability ( -sampling), and likelihoods associated to these two sampling schemes are not directly comparable (Stadler 2009; Lambert 2017); and (iii) previous simulations have shown that these models tend to over-fit the data when speciation decreases toward the present regardless the cause of decline (Etienne et al. 2016; Condamine 2018). This latter artifact might affect more than $78 \%$ of clades in our study, since we found most phylogenies are characterized by constant or decreasing rates through time (see Results ). Nonetheless, we acknowledge that the role of biotic interactions in explaining Neotropical diversity remains to be tested.

Acknowledgments. We thank all researchers who shared their published data through databases or to us directly (Drs. Arevalo, Martins, Fortes Santos, Simon, Lohmann, Mendoza, Swenson, Erkens, van der Meijden, and Freitas), Dr. Sanmartín and Dr. Manzano for invaluable comments on the manuscript and analyses. This work was funded by an "Investissements d'Avenir" grant managed by the Agence Nationale de la Recherche (CEBA, ref. ANR-10-LABX-25-01) and by the ANR GAARAnti project (ANR-17-CE310009). A.A. is supported by the Knut and Alice Wallenberg Foundation, the Swedish Research Council, the Swedish Foundation for Strategic Research, and the Royal Botanic Gardens, Kew.

\section{Citing references in text}

Allen, A.P., Gillooly, J.F., Savage, V.M. \& Brown, J.H. (2006). Kinetic effects of temperature on rates of genetic divergence and speciation.Proc. Natl. Acad. Sci. , 103, 9130-9135.

Antoine, P.O., Roddaz, M., Brichau, S., Tejada-Lara, J., Salas-Gismondi, R., Altamirano, A., et al. (2013). Middle Miocene vertebrates from the Amazonian Madre de Dios Subandean Zone, Perú. J. South Am. Earth Sci. , 42, 91-102.

Antonelli, A., Ariza, M., Albert, J., Andermann, T., Azevedo, J., Bacon, C., et al. (2018a). Conceptual and empirical advances in Neotropical biodiversity research. PeerJ , 6, e5644.

Antonelli, A., Kissling, W.D., Flantua, S.G.A., Bermúdez, M.A., Mulch, A., Muellner-Riehl, A.N., et al. (2018b). Geological and climatic influences on mountain biodiversity. Nat. Geosci., 11, 718.

Antonelli, A., Nylander, J. a a, Persson, C. \& Sanmartín, I. (2009). Tracing the impact of the Andean uplift on Neotropical plant evolution.Proc. Natl. Acad. Sci. U. S. A. , 106, 9749-9754.

Antonelli, A. \& Sanmartín, I. (2011). Why are there so many plant species in the Neotropics? Taxon , 60, 403-414.

Antonelli, A., Zizka, A., Carvalho, F.A., Scharn, R., Bacon, C.D., Silvestro, D., et al. (2018c). Amazonia is the primary source of Neotropical biodiversity. Proc. Natl. Acad. Sci. U. S. A., 115, 6034-6039.

Armijo, R., Lacassin, R., Coudurier-Curveur, A. \& Carrizo, D. (2015). Coupled tectonic evolution of Andean orogeny and global climate.Earth-Science Rev. , 143, 1-35.

Bacon, C.D., Velásquez-Puentes, F.J., Hoorn, C. \& Antonelli, A. (2018). Iriarteeae palms tracked the uplift of Andean Cordilleras. J. Biogeogr., 45, 1653-1663. 
Bininda-Emonds, O.R.P., Cardillo, M., Jones, K.E., MacPhee, R.D.E., Beck, R.M.D., Grenyer, R., et al. (2007). The delayed rise of present-day mammals. Nature , 446, 507-512.

Blisniuk, P.M., Stern, L.A., Chamberlain, C.P., Idleman, B. \& Zeitler, P.K. (2005). Climatic and ecologic changes during Miocene surface uplift in the Southern Patagonian Andes. Earth Planet. Sci. Lett. , 230, $125-142$.

Chazot, N., Willmott, K.R., Lamas, G., Freitas, A.V.L., Piron-Prunier, F., Arias, C.F., et al. (2019). Renewed diversification following Miocene landscape turnover in a Neotropical butterfly radiation. Glob. Ecol. Biogeogr. , DOI: 10.11.

Chen, Y.-W., Wu, J. \& Suppe, J. (2019). Southward propagation of Nazca subduction along the Andes. Nature , 565, 441-447.

Chomicki, G., Weber, M., Antonelli, A., Bascompte, J. \& Kiers, E.T. (2019). The Impact of Mutualisms on Species Richness. Trends Ecol. Evol.

Condamine, F.L. (2018). Limited by the roof of the world: mountain radiations of Apollo swallowtails controlled by diversity-dependence processes. Biol. Lett. , 14, 20170622.

Condamine, F.L., Rolland, J. \& Morlon, H. (2013). Macroevolutionary perspectives to environmental change. Ecol. Lett. , 16, 72-85.

Condamine, F.L., Rolland, J. \& Morlon, H. (2019). Assessing the causes of diversification slowdowns: temperature-dependent and diversity-dependent models receive equivalent support. Ecol. Lett. , 0.

Davis, M.P., Midford, P.E. \& Maddison, W. (2013). Exploring power and parameter estimation of the BiSSE method for analyzing species diversification. BMC Evol. Biol. , 13, 38.

Drummond, C.S., Eastwood, R.J., Miotto, S.T.S. \& Hughes, C.E. (2012). Multiple continental radiations and correlates of diversification inLupinus (Leguminosae): testing for key innovation with incomplete taxon sampling. Syst. Biol. , 61, 443-460.

Elsen, P.R. \& Tingley, M.W. (2015). Global mountain topography and the fate of montane species under climate change. Nat. Clim. Chang., 5, 772.

Esquerré, D., Brennan, I.G., Catullo, R.A., Torres-Pérez, F. \& Keogh, J.S. (2019). How mountains shape biodiversity: The role of the Andes in biogeography, diversification, and reproductive biology in South America's most species-rich lizard radiation (Squamata: Liolaemidae).Evolution, https://do.

Etienne, R.S., Haegeman, B., Stadler, T., Aze, T., Pearson, P.N., Purvis, A., et al. (2012). Diversitydependence brings molecular phylogenies closer to agreement with the fossil record. Proc. R. Soc. London B , 279, 1300-1309.

Etienne, R.S., Pigot, A.L. \& Phillimore, A.B. (2016). How reliably can we infer diversity-dependent diversification from phylogenies? Methods Ecol. Evol. , 7, 1092-1099.

Fjeldsa, J., Bowie, R.C.K. \& Rahbek, C. (2012). The role of mountain ranges in the diversification of birds. Annu. Rev. Ecol. Evol. Syst. , 43, 249-265.

Flantua, S.G.A., O'dea, A., Onstein, R.E., Giraldo, C. \& Hooghiemstra, H. (2019). The flickering connectivity system of the north Andean paramos. J. Biogeogr.

Fouquet, A., Santana Cassini, C., Fernando Baptista Haddad, C., Pech, N. \& Trefaut Rodrigues, M. (2014). Species delimitation, patterns of diversification and historical biogeography of the Neotropical frog genus Adenomera (Anura, Leptodactylidae). J. Biogeogr. , 41, 855-870.

Garzione, C.N., Hoke, G.D., Libarkin, J.C., Withers, S., MacFadden, B., Eiler, J., et al. (2008). Rise of the Andes. Science, 320, 1304-1307. 
Gentry, A.H. (1982). Neotropical floristic diversity: phytogeographical connections between Central and South America, Pleistocene climatic fluctuations, or an accident of the Andean orogeny? Ann. - Missouri Bot. Gard. , 69, 557-593.

Gillooly, J.F., Brown, J.H., West, G.B., Savage, V.M. \& Charnov, E.L. (2001). Effects of Size and Temperature on Metabolic Rate.Science, 293, 2248 LP - 2251.

Haffer, J. (1969). Speciation in Amazon forest birds. Science, 165, 131-137.

Hoorn, C., Bogota-A, G.R., Romero-Baez, M., Lammertsma, E.I., Flantua, S.G.A., Dantas, E.L., et al. (2017). The Amazon at sea: Onset and stages of the Amazon River from a marine record, with special reference to Neogene plant turnover in the drainage basin. Glob. Planet. Change, 153, 51-65.

Hoorn, C., Guerrero, J., Sarmiento, G.A. \& Lorente, M.A. (1995). Andean tectonics as a cause for changing drainage patterns in Miocene northern South America. Geology , 23, 237-240.

Hoorn, C., Wesselingh, F.P., Ter Steege, H., Bermudez, M.A., Mora, A., Sevink, J., et al. (2010). Amazonia through time: Andean uplift, climate change, landscape evolution, and biodiversity. Science, 330, 927-931.

Hughes, C. \& Eastwood, R. (2006). Island radiation on a continental scale: Exceptional rates of plant diversification after uplift of the Andes. Proc. Natl. Acad. Sci. U. S. A., 103, 10334-10339.

Hutter, C.R., Guayasamin, J.M. \& Wiens, J.J. (2013). Explaining Andean megadiversity: the evolutionary and ecological causes of glassfrog elevational richness patterns. Ecol. Lett. , 16, 1135-1144.

Hutter, C.R., Lambert, S.M. \& Wiens, J.J. (2017). Rapid diversification and time explain Amphibian richness at different scales in the tropical Andes, Earth's most biodiverse Hotspot. Am. Nat. , 190, 828-843.

Jansson, R., Rodriguez-Castaneda, G. \& Harding, L.E. (2013). What can multiple phylogenies say about the latitudinal diversity gradient? A new look at the tropical conservatism, out of the tropics, and diversification rate hypotheses. Evolution, 67, 1741-1755.

Jaramillo, C. (2019). 140 million years of tropical biome evolution. In: The Geology of Colombia (ed. Gomez, J.). Colombian Geological Survey, Bogota, Colombia.

Jaramillo, C. \& Cardenas, A. (2013). Global warming and neotropical rainforests: a historical perspective. Annu. Rev. Earth Planet. Sci. , 41, 741-766.

Jaramillo, C., Rueda, M.J. \& Mora, G. (2006). Cenozoic plant diversity in the Neotropics. Science, 311, 1893-1896.

Jaramillo, C.A. (2018). Evolution of the Isthmus of Panama: biological, paleoceanographic and paleoclimatological implications. Mt. Clim. biodiversity. Oxford Wiley Blackwell , 323-338.

Jetz, W., Thomas, G.H., Joy, J.B., Hartmann, K. \& Mooers, A.O. (2012). The global diversity of birds in space and time. Nature, 491, 444-448.

Kozak, K.H. \& Wiens, J.J. (2010). Accelerated rates of climatic-niche evolution underlie rapid species diversification. Ecol. Lett. , 13, 1378-1389.

Kuhn, T.S., Mooers, A. \& Thomas, G.H. (2011). A simple polytomy resolver for dated phylogenies. Methods Ecol. Evol. , 2, 427-436.

Kursar, T.A., Dexter, K.G., Lokvam, J., Pennington, R.T., Richardson, J.E., Weber, M.G., et al. (2009). The evolution of antiherbivore defenses and their contribution to species coexistence in the tropical tree genus Inga . Proc. Natl. Acad. Sci. , 106, 18073-18078.

Lagomarsino, L.P., Condamine, F.L., Antonelli, A., Mulch, A. \& Davis, C.C. (2016). The abiotic and biotic drivers of rapid diversification in Andean bellflowers (Campanulaceae). New Phytol. , 210, 1430-1442. 
Lambert, A. (2017). The genealogy of a sample from a binary branching process. arXiv Prepr.

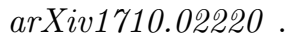

Leigh Jr, E.G., Davidar, P., Dick, C.W., Terborgh, J., Puyravaud, J., ter Steege, H., et al. (2004). Why do some tropical forests have so many species of trees? Biotropica , 36, 447-473.

Luebert, F. \& Weigend, M. (2014). Phylogenetic insights into Andean plant diversification. Front. Ecol. Evol. , doi:10.338.

Luzuriaga-Aveiga, V.E. \& Weir, J.T. (2019). Elevational differentiation accelerates trait evolution but not speciation rates in Amazonian birds.Ecol. Lett. , 22, 624-633.

Madrinan, S., Cortes, A. \& Richardson, J. (2013). Paramo is the world's fastest evolving and coolest biodiversity hotspot. Front. Genet.

Mayhew, P.J., Bell, M.A., Benton, T.G. \& McGowan, A.J. (2012). Biodiversity tracks temperature over time. Proc. Natl. Acad. Sci. , 109, 15141-15145.

McPeek, M.A. (2008). The ecological dynamics of clade diversification and community assembly. Am. Nat. , 172, E270-E284.

Meseguer, A.S., Lobo, J.M., Cornuault, J., Beerling, D., Ruhfel, B.R., Davis, C.C., et al. (2018). Reconstructing deep-time paleoclimate legacies in the clusioid Malpighiales unveils their role in the evolution and extinction of the boreotropical flora. Glob. Ecol. Biogeogr. , 27, 616-628.

Mittelbach, G.G., Schemske, D.W., Cornell, H. V, Allen, A.P., Brown, J.M., Bush, M.B., et al. (2007). Evolution and the latitudinal diversity gradient: speciation, extinction and biogeography. Ecol. Lett. , 10, $315-331$.

Mittermeier, R.A., Turner, W.R., Larsen, F.W., Brooks, T.M. \& Gascon, C. (2011). Global biodiversity conservation: the critical role of hotspots. In: Biodiversity Hotspots (eds. Zachos, F.E. \& Habel, J.C.). Springer-Verlag, Berlin Heidelberg, Germany, pp. 3-22.

Moen, D. \& Morlon, H. (2014). Why does diversification slow down? Trends Ecol. Evol. , 29, 190-197.

Moen, D.S. \& Wiens, J.J. (2017). Microhabitat and climatic niche change explain patterns of diversification among frog families. Am. Nat. , 190, 29-44.

Moritz, C., Patton, J.L., Schneider, C.J. \& Smith, T.B. (2000). Diversification of rainforest faunas: An integrated molecular approach.Annu. Rev. Ecol. Syst. , 31, 533-563.

Morlon, H., Lewitus, E., Condamine, F.L., Manceau, M., Clavel, J. \& Drury, J. (2016). RPANDA: an R package for macroevolutionary analyses on phylogenetic trees. Methods Ecol. Evol. , 7, 589-597.

Morlon, H., Parsons, T.L. \& Plotkin, J.B. (2011). Reconciling molecular phylogenies with the fossil record. Proc. Natl. Acad. Sci. , 108, 16327-16332.

Morlon, H., Potts, M.D. \& Plotkin, J.B. (2010). Inferring the dynamics of diversification: a coalescent approach. PLOS Biol. , 8, e1000493.

Olalla-Tarraga, M.A., McInnes, L., Bini, L.M., Diniz-Filho, J.A.F., Fritz, S.A., Hawkins, B.A., et al. (2011). Climatic niche conservatism and the evolutionary dynamics in species range boundaries: global congruence across mammals and amphibians. J. Biogeogr. , 38, 2237-2247.

Perez-Escobar, O.A., Chomicki, G., Condamine, F.L., Karremans, A.P., Bogarin, D., Matzke, N.J., et al. (2017). Recent origin and rapid speciation of Neotropical orchids in the world's richest plant biodiversity hotspot. New Phytol. , 215, 891-905.

Phillimore, A.B. \& Price, T.D. (2008). Density-dependent cladogenesis in birds. PLOS Biol. , 6, e71. 
Pie, M.R., Campos, L.L.F., Meyer, A.L.S. \& Duran, A. (2017). The evolution of climatic niches in squamate reptiles. Proc. R. Soc. B Biol. Sci., 284, 1858.

Pinto-Ledezma, J.N., Simon, L.M., Diniz-Filho, J.A.F. \& Villalobos, F. (2017). The geographical diversification of Furnariides: the role of forest versus open habitats in driving species richness gradients.J. Biogeogr. , 44, 1683-1693.

Pouchon, C., Boyer, F., Lavergne, S., Mavarez, J., Aubert, S., Fernandez, A., et al. (2018). Phylogenomic analysis of the explosive adaptive radiation of the Espeletia Complex (Asteraceae) in the Tropical Andes. Syst. Biol. , 67, 1041-1060.

Prokoph, A., Shields, G.A. \& Veizer, J. (2008). Compilation and time-series analysis of a marine carbonate 818O, $813 \mathrm{C}, 87 \mathrm{Sr} / 86 \mathrm{Sr}$ and $834 \mathrm{~S}$ database through Earth history. Earth-Science Rev. , 87, 113-133.

Pyron, R.A. (2014). Biogeographic analysis reveals ancient continental vicariance and recent oceanic dispersal in amphibians. Syst. Biol. , 63, 779-797.

Pyron, R.A. \& Burbrink, F.T. (2014). Early origin of viviparity and multiple reversions to oviparity in squamate reptiles. Ecol. Lett. , 17, 13-21.

Rabosky, D.L. (2009). Ecological limits and diversification rate: alternative paradigms to explain the variation in species richness among clades and regions. Ecol. Lett. , 12, 735-743.

Rabosky, D.L., Donnellan, S.C., Grundler, M. \& Lovette, I.J. (2014). Analysis and visualization of complex macroevolutionary dynamics: an example from Australian scincid lizards. Syst. Biol. , 63, 610-627.

Richardson, J.-E., Pennington, T.-D. \& Hollingsworth, P.-M. (2001). Rapid diversification of a species-rich genus of neotropical rain forest trees. Science , 293, 2242-2245.

Rowan, J., Beaudrot, L., Franklin, J., Reed, K.E., Smail, I.E., Zamora, A., et al. (2019). Geographically divergent evolutionary and ecological legacies shape mammal biodiversity in the global tropics and subtropics. Proc. Natl. Acad. Sci.

Rull, V. (2011a). Neotropical biodiversity: Timing and potential drivers. Trends Ecol. Evol. , 26, 508-513.

Rull, V. (2011b). Origins of biodiversity. Science, 331, 398-399.

Salas-Gismondi, R., Flynn, J.J., Baby, P., Tejada-Lara, J. V, Wesselingh, F.P. \& Antoine, P.-O. (2015). A Miocene hyperdiverse crocodylian community reveals peculiar trophic dynamics in proto-Amazonian megawetlands. Proc. R. Soc. B Biol. Sci., 282, 20142490.

Santos, J.C., Coloma, L.A. \& Summers, K. (2009). Amazonian amphibian diversity is primarily derived from late Miocene Andean lineages.PLoS Biol. , 7, e1000056.

Silva, G.A.R., Antonelli, A., Lendel, A., Moraes, E. de M. \& Manfrin, M.H. (2018). The impact of early Quaternary climate change on the diversification and population dynamics of a South American cactus species. J. Biogeogr. , 45, 76-88.

Silva, S.M., Peterson, A.T., Carneiro, L., Burlamaqui, T.C.T., Ribas, C.C., Sousa-Neves, T., et al. (2019). A dynamic continental moisture gradient drove Amazonian bird diversification. Sci. Adv. , 5, eaat5752.

Simon, M.F., Grether, R., de Queiroz, L.P., Skema, C., Pennington, R.T. \& Hughes, C.E. (2009). Recent assembly of the Cerrado, a neotropical plant diversity hotspot, by in situ evolution of adaptations to fire.Proc. Natl. Acad. Sci. , 106, 20359-20364.

Simpson, G.G. (1980). Splendid isolation: the curious history of South American mammals . Yale University Press.

Smith, B.T., McCormack, J.E., Cuervo, A.M., Hickerson, M.J., Aleixo, A., Cadena, C.D., et al. (2014). The drivers of tropical speciation. Nature , 515, 406-409. 
Springer, M.S., Meredith, R.W., Gatesy, J., Emerling, C.A., Park, J., Rabosky, D.L., et al. (2012). Macroevolutionary dynamics and historical biogeography of primate diversification inferred from a species supermatrix. PLoS One, 7, e49521.

Stadler, T. (2009). On incomplete sampling under birth-death models and connections to the sampling-based coalescent. J. Theor. Biol. , 261, 58-66.

Stebbins, G.L. (1974). Flowering plants: evolution above the species level . Harvard University Press, Cambridge, Massachusetts.

Veizer, J. \& Prokoph, A. (2015). Temperatures and oxygen isotopic composition of Phanerozoic oceans. Earth-Science Rev. , 146, 92-104.

Wallace, A.R. (1878). Tropical nature, and other essays . Macmillan, London.

Weir, J.T. (2006). Divergent timing and patterns of species accumulation in lowland and highland neotropical birds. Evolution, 60, 842-855.

Wiens, J.J. (2017). What explains patterns of biodiversity across the Tree of Life? New research is revealing the causes of the dramatic variation in species numbers across branches of the Tree of Life.BioEssays , 39, 1600128.

Zachos, J.C., Dickens, G.R. \& Zeebe, R.E. (2008). An early Cenozoic perspective on greenhouse warming and carbon-cycle dynamics.Nature , 451, 279-283.

Zanne, A.E., Tank, D.C., Cornwell, W.K., Eastman, J.M., Smith, S.A., FitzJohn, R.G., et al. (2014). Three keys to the radiation of angiosperms into freezing environments. Nature , 506, 89-92. 


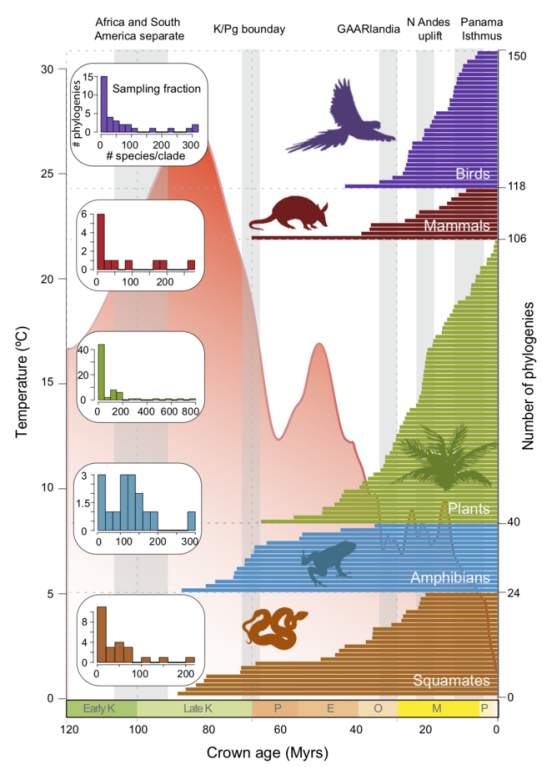

Figure 1. Time of origin for Neotropical tetrapods and plants. Horizontal bars represent crown ages of 150 phylogenies analysed in this study. Shaded boxes represent the approximate duration of some geological events suggested to have fostered dispersal and diversification of Neotropical organisms. Inset histograms represent number of species sampled per clade (mean $=83.5$ species). Mean global temperature curve from (Zachos et al. 2008). Abbreviations: K, Cretaceous; P, Paleocene; E, Eocene; O, Oligocene; M, Miocene; P, Pliocene (Pleistocene follows but is not shown); GAARlandia, Greater Antilles and Aves Ridge. Animal and plant silhouettes from PhyloPic (http://phylopic.org/). 


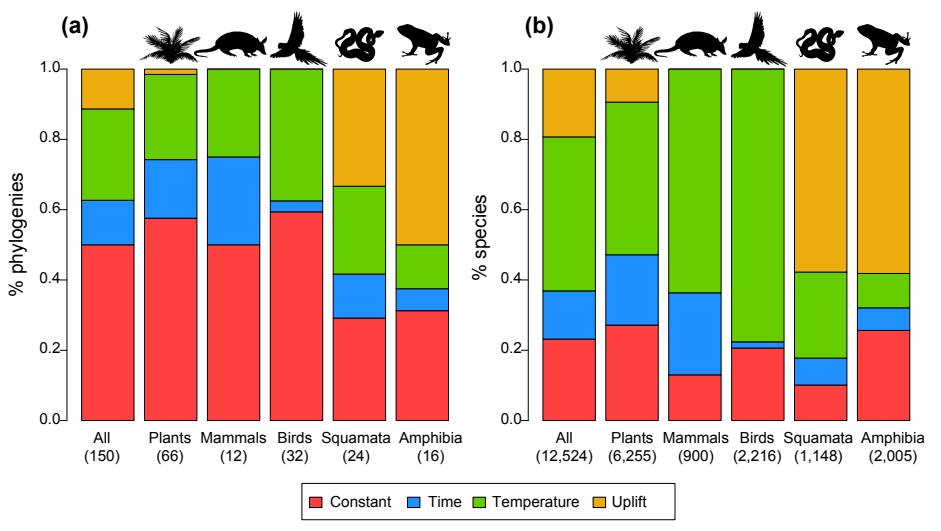

Figure 2. Drivers of Neotropical diversification. The histograms report the proportion of (a) phylogenies and (b) species whose diversification rates are best explained by a model with constant, time-dependent, temperature-dependent, or uplift-dependent diversification. The number of phylogenies (and species) per group is shown in parentheses. Constant diversification models find most support when whole Neotropical tetrapod and plant phylogenies are considered, while temperature-dependent models find most support considering total species richness. 


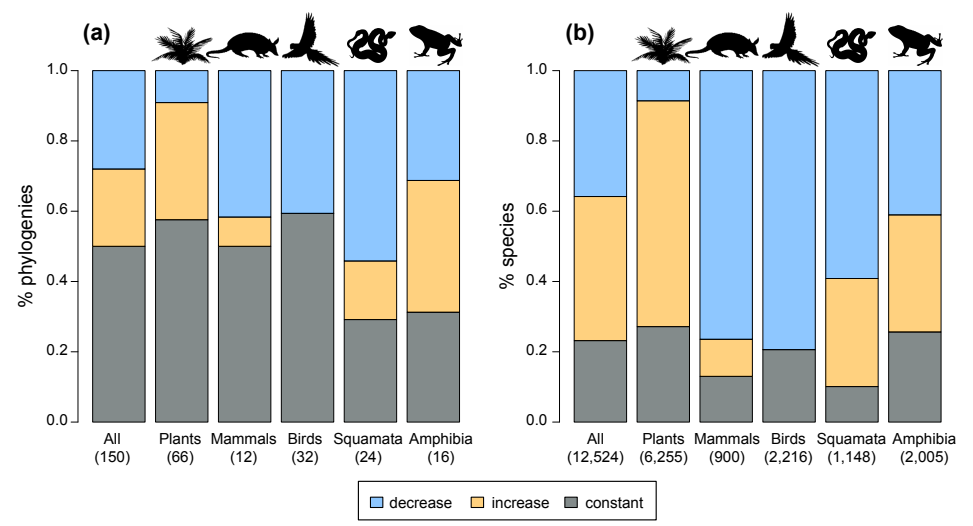

Figure 3. Tempo of Neotropical diversification. The histograms report the proportion of (a) phylogenies and (b) species that are best explained by a model with diversification rates that are constant, decreasing, or increasing toward the present. The number of phylogenies (and species) per group is shown in parentheses. Diversification rates tend to decrease towards the present across Neotropical tetrapods and increase for Neotropical plants, with similar proportions of constant rates between plants and tetrapods. 

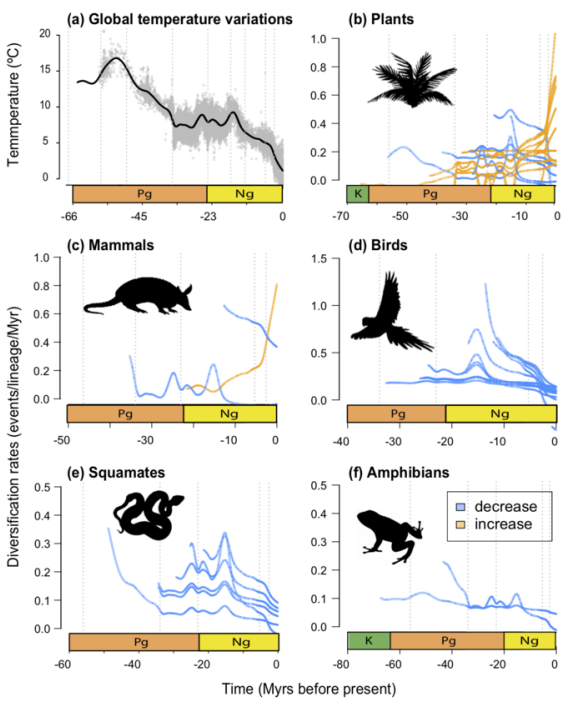

Figure 4. Diversification responses to past temperature changes. (a) Global deep-sea temperature variations as estimated in (Zachos et al. 2008). The curves in (b-f) show diversification rates of each of the 39 clades of plants (b), mammals (c), birds (d), squamates (e), and amphibians $(\boldsymbol{f})$ that best support a temperature-dependent diversification model. Diversification rates of tetrapods tend to decline toward the present (positive dependence) while rates tend to increase for plant (negative dependence) as a result of climatic cooling. 

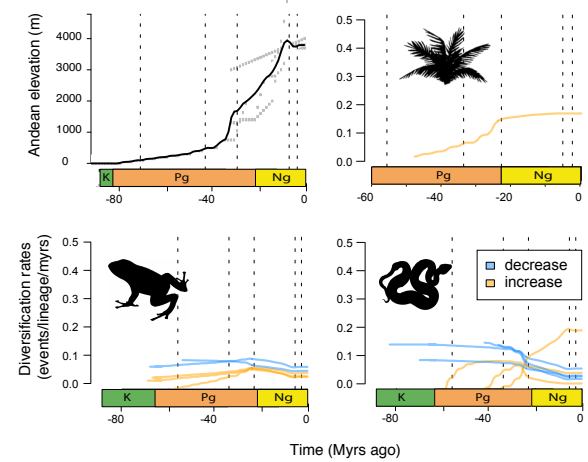

Figure 5. Diversification responses to the Andean uplift. (a) Mean altitudinal variation of the Andes through time as compiled in (Lagomarsino et al. 2016). The curves in (b-d) represent diversification rates of each of the 17 clades of plants (b), squamates (c) and amphibians (d) that best support an uplift-dependent diversification model. Diversification rates of Neotropical plants tend to increase with the uplift of the Andes, while Neotropical squamates and amphibians show contrasting responses (increases and decreases) to Andean uplift. Bird and mammal clades do not support an uplift-dependent model. 